\title{
Transcranial Focal Electrical Stimulation Modifies Biogenic Amines' Alterations Induced by 6-Hydroxydopamine in Rat Brain
}

\author{
Cesar Emmanuel Santana-Gómez ${ }^{1,+}$, Daniel Pérez-Pérez ${ }^{2,+} \mathbb{D}^{\mathbb{D}}$, Daniel Fonseca-Barriendos ${ }^{3}$ (D), \\ Oscar Arias-Carrión ${ }^{4}$, Walter Besio ${ }^{5, * \mathbb{D}}$ and Luisa Rocha ${ }^{3, *(\mathbb{D})}$
}

Citation: Santana-Gómez, C.E.; Pérez-Pérez, D.; Fonseca-Barriendos, D.; Arias-Carrión, O.; Besio, W.; Rocha, L. Transcranial Focal Electrical Stimulation Modifies Biogenic Amines' Alterations Induced by 6-Hydroxydopamine in Rat Brain. Pharmaceuticals 2021, 14, 706. https://doi.org/10.3390/ph14080706

\section{Academic Editors: Antoni}

Camins Espuny, Miren Ettcheto and Angela De Simone

Received: 8 May 2021

Accepted: 19 July 2021

Published: 21 July 2021

Publisher's Note: MDPI stays neutral with regard to jurisdictional claims in published maps and institutional affiliations.

Copyright: (c) 2021 by the authors. Licensee MDPI, Basel, Switzerland. This article is an open access article distributed under the terms and conditions of the Creative Commons Attribution (CC BY) license (https:// creativecommons.org/licenses/by/ $4.0 /)$.
1 Department of Neurology, David Geffen School of Medicine at UCLA, Los Angeles, CA 90095, USA; csantanagomez@mednet.ucla.edu

2 Plan of Combined Studies in Medicine (PECEM), Faculty of Medicine, UNAM, México City 04510, Mexico; perez_dani18@hotmail.com

3 Pharmacobiology Department, Center for Research and Advanced Studies, México City 14330, Mexico; daniel.fonseca@cinvestav.mx

4 Unidad de Trastornos del Movimiento y Sueño, Hospital General Dr. Manuel Gea González, Secretaria de Salud, Mexico City 14080, Mexico; arias@iNeuron.mx

5 Department of Electrical, Computer, and Biomedical Engineering, University of Rhode Island, Kingston, RI 02881, USA

* Correspondence: besio@uri.edu (W.B.); lrocha@cinvestav.mx (L.R.)

$+\quad$ These authors contributed equally.

Abstract: Transcranial focal stimulation (TFS) is a non-invasive neuromodulation strategy with neuroprotective effects. On the other hand, 6-hidroxidopamine (6-OHDA) induces neurodegeneration of the nigrostriatal system producing modifications in the dopaminergic, serotoninergic, and histaminergic systems. The present study was conducted to test whether repetitive application of TFS avoids the biogenic amines' changes induced by the intrastriatal injection of 6-OHDA. Experiments were designed to determine the tissue content of dopamine, serotonin, and histamine in the brain of animals injected with 6-OHDA and then receiving daily TFS for 21 days. Tissue content of biogenic amines was evaluated in the cerebral cortex, hippocampus, amygdala, and striatum, ipsiand contralateral to the side of 6-OHDA injection. Results obtained were compared to animals with 6-OHDA, TFS alone, and a Sham group. The present study revealed that TFS did not avoid the changes in the tissue content of dopamine in striatum. However, TFS was able to avoid several of the changes induced by 6-OHDA in the tissue content of dopamine, serotonin, and histamine in the different brain areas evaluated. Interestingly, TFS alone did not induce significant changes in the different brain areas evaluated. The present study showed that repetitive TFS avoids the biogenic amines' changes induced by 6-OHDA. TFS can represent a new therapeutic strategy to avoid the neurotoxicity induced by 6-OHDA.

Keywords: non-invasive neuromodulation; 6-hidroxidopamine; dopamine; serotonin; histamine; transcranial focal stimulation

\section{Introduction}

The electrical modulation of the brain induced by strategies such as deep brain stimulation and vagal nerve stimulation has been considered an alternative treatment to control neurological disorders such as Parkinson's disease and pharmacoresistant epilepsy [1-3]. However, these strategies of neuromodulation are invasive and have high economical costs $[4,5]$.

On the one hand, transcranial focal stimulation (TFS) applied via tripolar concentric ring electrodes (TCREs) is a non-invasive strategy of neuromodulation that induces inhibitory and neuroprotective effects. TFS decreases the expression of the convulsive 
activity produced by pilocarpine, penicillin, and pentylenetetrazole [6-9]. TFS combined with sub-effective doses of diazepam reduces the incidence of mild and severe generalized pilocarpine-induced seizures, an effect associated with lower neuronal damage [10]. We recently found that TFS avoids the P-glycoprotein overexpression induced after an acute convulsive seizure and enhances the phenytoin effects in an experimental model of drug-resistant seizures [11]. The neuroprotective effects of TFS have been associated with lessened evoked glutamate release in vivo [12].

On the other hand, 6-hydroxydopamine (6-OHDA) is a toxin used to induce selective damage of catecholaminergic neurons and neurodegeneration of the nigrostriatal system [13]. The neurotoxicity induced by 6-OHDA is explained by the oxidative stress that results from the generation of reactive oxygen species (ROS) as a consequence of its auto-oxidation [14]. This condition associated with augmented free calcium can lead to cell death [15]. 6-OHDA is widely used to reproduce some of Parkinson's disease signs as a result of neuroinflammation, neurodegeneration, apoptosis [16], and loss of dopaminergic neurons in the brain area injected [17].

In addition to the disruption of dopaminergic neurotransmission, 6-OHDA also modifies the neurotransmission mediated by other biogenic amines. The bilateral medial forebrain bundle 6-OHDA injection reduces serotonin tissue levels in the striatum [18]. 6-OHDA significantly augments histamine content in different brain areas (hypothalamus, hippocampus, and medulla oblongata) [19], a condition that facilitates neurodegeneration induced by the toxin [20].

It is described that neuromodulation strategies modify the neurotransmission mediated by histamine [21], serotonin, and dopamine [22]. The present study was designed to support the hypothesis that repetitive application of TFS can reduce the neurotoxic effects induced by 6-OHDA. Experiments were designed to evaluate the tissue content of dopamine, serotonin, and histamine in different brain areas of animals treated with an intrastriatal injection of 6-OHDA and subsequent repetitive application of TFS.

\section{Results}

\subsection{TFS Did Not Alter the Tissue Content of Biogenic Amines}

The Sham group showed the following tissue content values of biogenic amines expressed in $\mu \mathrm{M} / \mathrm{mg}$ of protein, ipsi- and contralateral to the place of vehicle injection: a) dopamine: striatum, $186 \pm 18$ and $229 \pm 20$, respectively; cortex, $11.6 \pm 1.8$ and $24.2 \pm 4.3$; hippocampus, $12.5 \pm 1$ and $15 \pm 1.7$, respectively; amygdala, $13.9 \pm 2.3$ and $18.3 \pm 1.2$, respectively; b) serotonin: striatum, $57 \pm 3$ and $62.9 \pm 6.2$, respectively; cortex, $57.9 \pm 7.5$ and $68.6 \pm 9$; hippocampus, $56.6 \pm 13$ and $70.1 \pm 6.1$, respectively; amygdala, $157.4 \pm 23$ and $174 \pm 10$, respectively; c) histamine: striatum, $14.4 \pm 1.6$ and $13.6 \pm 1.2$, respectively; cortex, $11.8 \pm 0.7$ and $14.2 \pm 1.6$; hippocampus, $14 \pm 1.1$ and $14.2 \pm 1.7$, respectively; amygdala, $12.7 \pm 0.7$ and $14.3 \pm 1.4$, respectively. TFS did not induce behavioral changes during its repetitive application to the TFS group. The tissue content of dopamine, serotonin, and histamine in the different brain areas of the TFS group was similar to the Sham group (Figures 1-3). These results suggest that TFS does not modify the normal brain function. 


\section{DOPAMINE}

\section{Ipsilateral Striatum Contralateral}
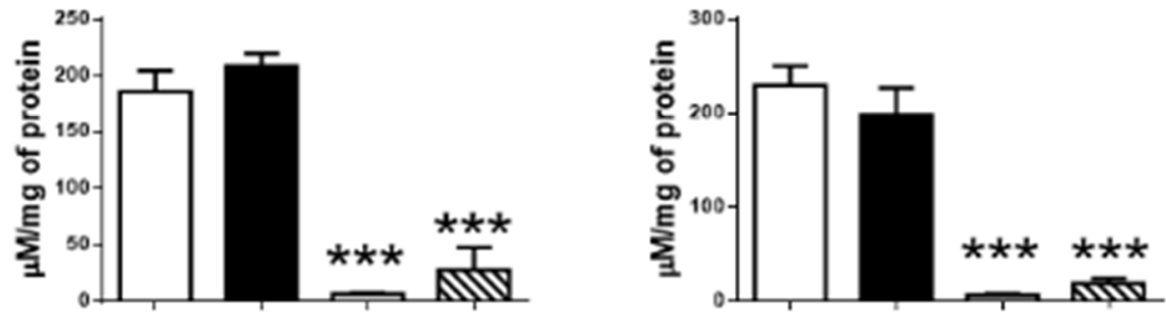

\section{Cortex}
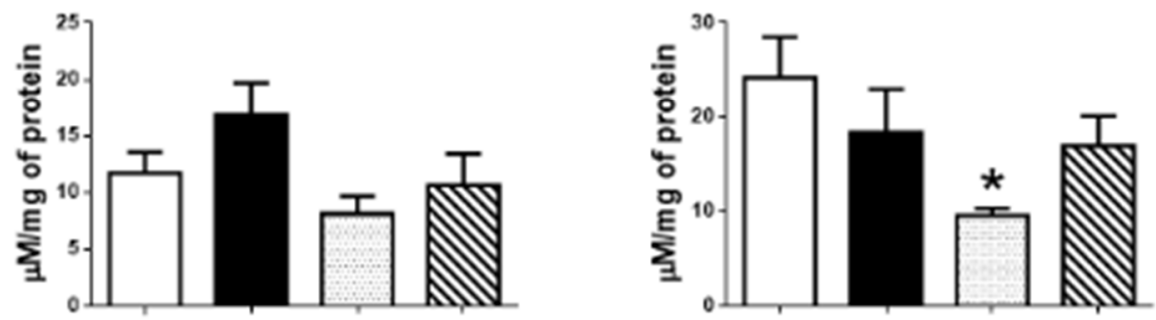

\section{Hippocampus}
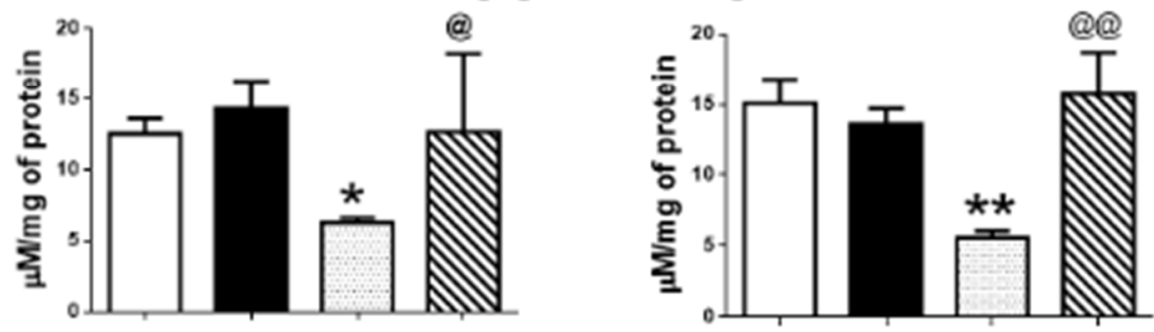

\section{Amygdala}
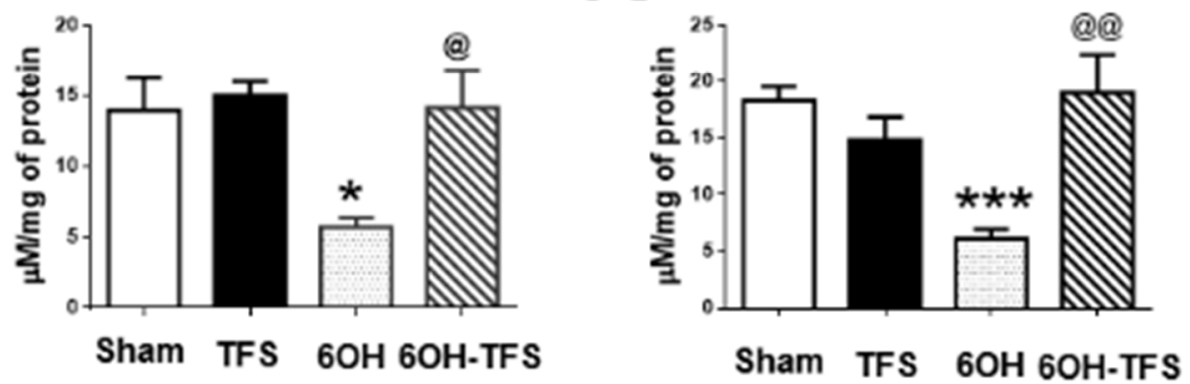

Figure 1. Effects of TFS on the changes in dopamine tissue content induced by 6-OHDA in different brain areas. Tissue content ipsi- and contralateral to the toxin injection or vehicle is expressed as $\mu \mathrm{M} / \mathrm{mg}$ of protein. Sham, animals with vehicle injection; TFS, animals receiving TFS daily for 21 days; $6 \mathrm{OH}$, rats injected with 6-OHDA; 6-OH-TFS, animals receiving repetitive TFS after 6-OHDA injection. Data are expressed as mean \pm standard error. ${ }^{*} p<0.05$ vs Sham group; ${ }^{* *} p<0.01$ vs Sham group; ${ }^{* * *} p<0.001$ vs Sham group; ${ }^{\circledR} p<0.05$ vs 6-OHDA group; ${ }^{\circledR}{ }^{\circ} p<0.01$ vs 6-OHDA group. The results obtained were analyzed with ANOVA followed by the post hoc Tukey test. 


\section{SEROTONIN}

\section{Ipsilateral Striatum Contralateral}

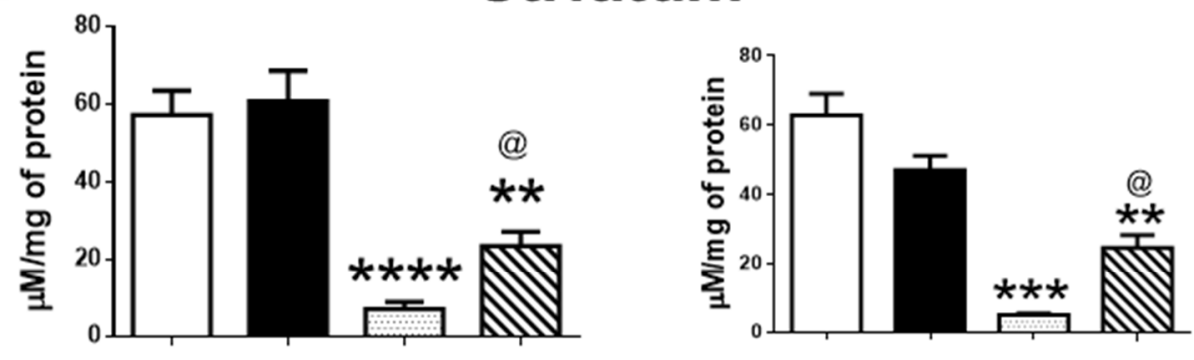

\section{Cortex}
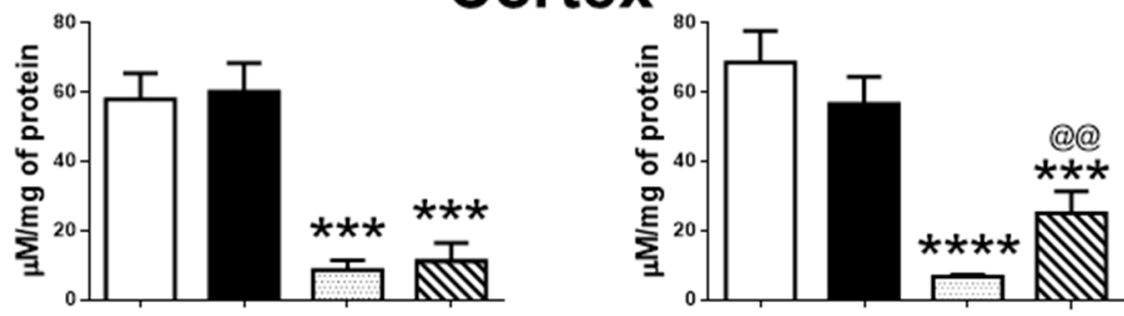

Hippocampus
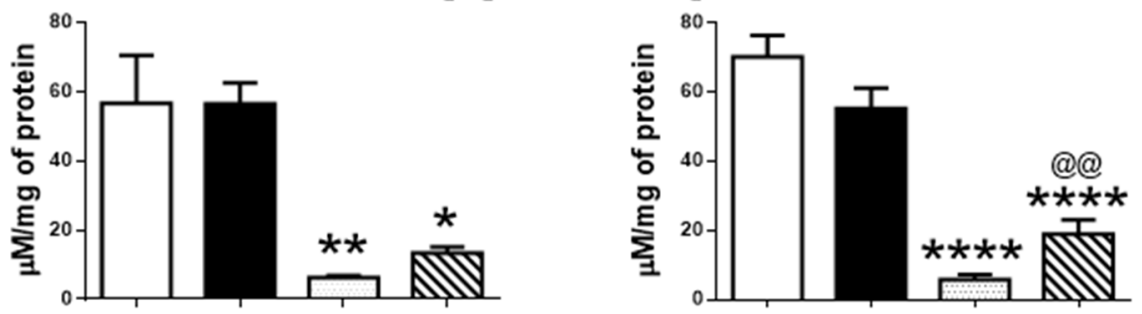

\section{Amygdala}
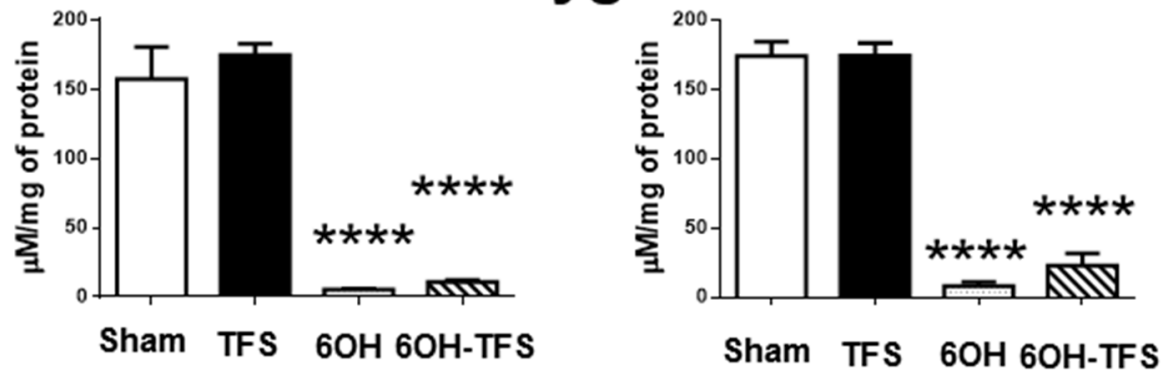

Figure 2. Effects of TFS on the changes in serotonin tissue content induced by 6-OHDA in different brain areas. Notations as in Figure 1. ${ }^{*} p<0.05$ vs Sham group; ${ }^{* *} p<0.01$ vs Sham group; ${ }^{* * *} p<0.001$ vs Sham group; ${ }^{* * *} p<0.0001$ vs Sham group; ${ }^{\circledR} p<0.05$ vs 6-OHDA group; ${ }^{\circledR} p<0.01$ vs 6-OHDA group. The results obtained were analyzed with ANOVA followed by the post hoc Tukey test. 


\section{HISTAMINE \\ Ipsilateral \\ Striatum \\ Contralateral}
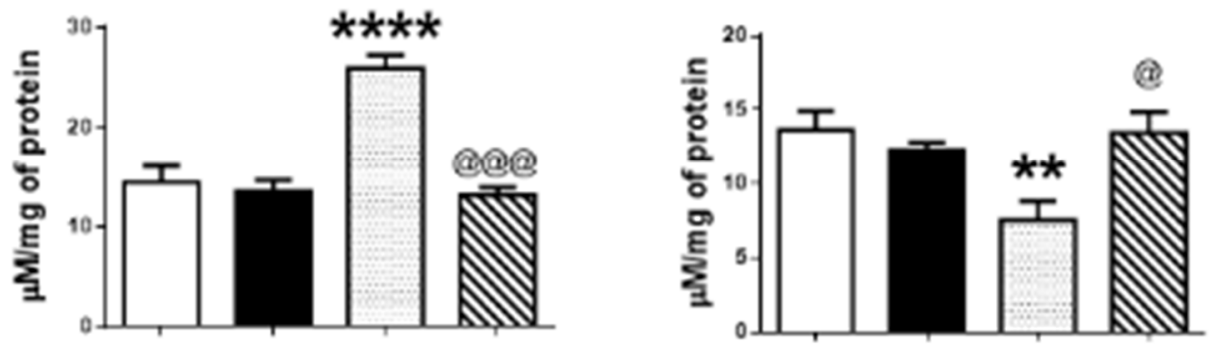

\section{Cortex}
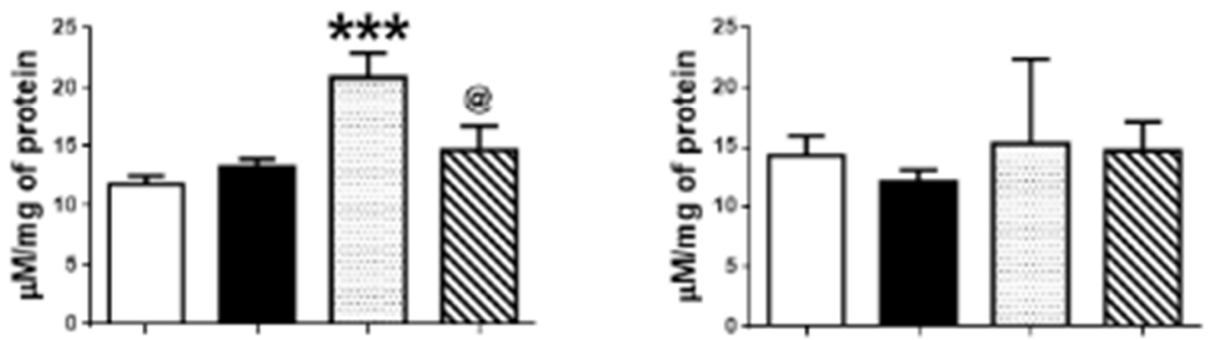

Hippocampus
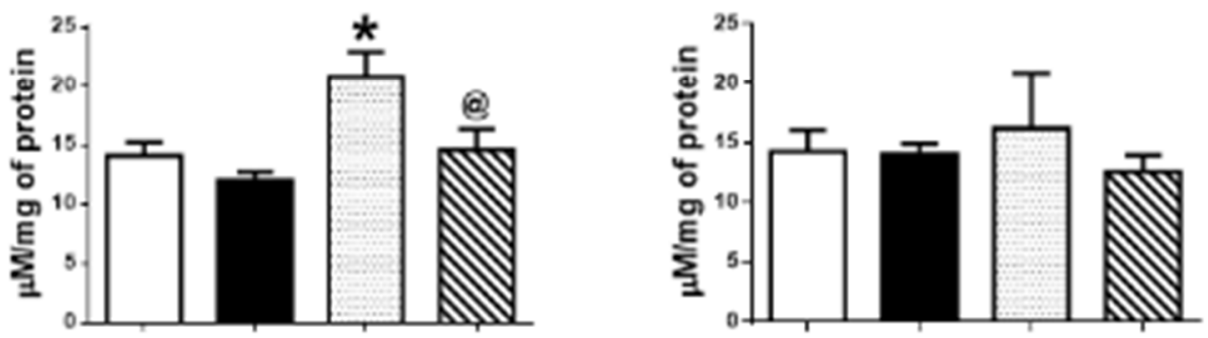

\section{Amygdala}
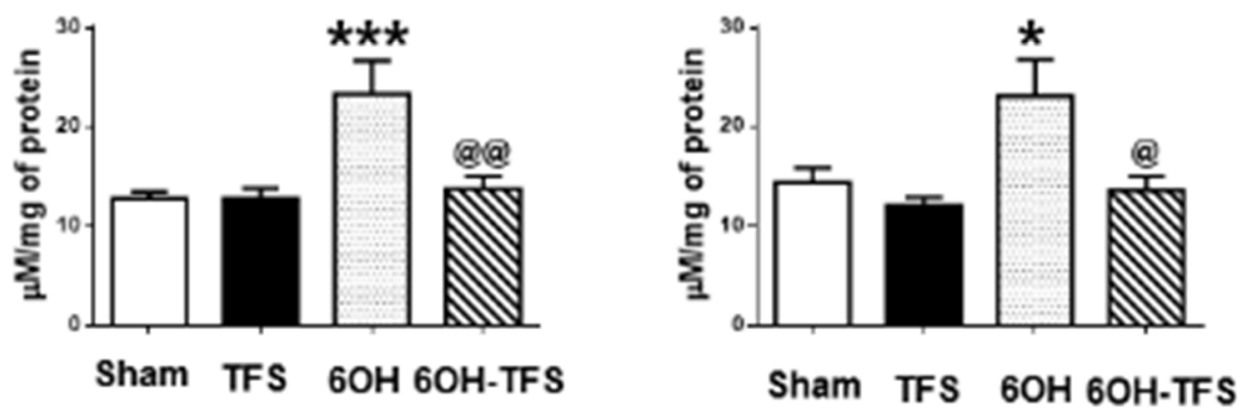

Figure 3. Effects of TFS on the changes of histamine tissue content induced by 6-OHDA in different brain areas. Notations as in Figure 1. ${ }^{*} p<0.05$ vs Sham group; ${ }^{* *} p<0.01$ vs Sham group; ${ }^{* *} p<0.001$ vs Sham group; ${ }^{* * *} p<0.0001$ vs Sham group; ${ }^{@} p<0.05$ vs 6-OHDA group; ${ }^{@ @ ~} p<0.01$ vs 6-OHDA group; ${ }^{@ @ @ ~} p<0.001$ vs 6-OHDA group. The results obtained were analyzed with ANOVA followed by the post hoc Tukey test. 


\subsection{Intrastriatal Administration of 6-OHDA Modifies the Brain Tissue Content of Biogenic Amines}

In contrast to the Sham group, animals from the 6-OHDA group showed a lower tissue content of dopamine in all the brain areas evaluated. This effect was more evident in the striatum, ipsi- and contralateral to the 6-OHDA administration ( $96 \%$ and $97 \%$, respectively, $p<0.0001$ vs Sham group) (Figure 1). Similarly, the tissue content of serotonin was lower in all cerebral structures analyzed (Figure 2). Concerning histamine and when compared with the Sham group, the 6-OHDA group presented high tissue content in ipsilateral striatum $(80 \%, p<0.0001)$, cortex $(76 \%, p<0.0006)$, and hippocampus $(48 \%, p<0.01)$; as well as bilateral amygdalae (ipsi- $82 \%, p<0.0009$; contra- $60 \%, p<0.01$ ). The experiments also revealed low histamine tissue content in the contralateral striatum $(45 \%, p<0.006)$ (Figure 3). According to the results obtained, 6-OHDA induces significant changes in the tissue content of biogenic amines in different brain areas, ipsi- and contralateral to a lesion.

\subsection{TFS Modifies the Changes in the Tissue Content of Biogenic Amines Induced by the Intrastriatal Administration of 6-OHDA}

Animals from the 6-OHDA-TFS group showed similarly low levels of dopamine tissue content in the striatum, ipsi- and contralateral to the side of toxin injection, when compared with the 6-OHDA group. However, the results obtained revealed that the other brain areas evaluated presented tissue content of dopamine similar to the Sham group. Indeed, the hippocampus and amygdala showed a significantly high tissue content of dopamine when compared with the 6-OHDA group (Figure 1).

The 6-OHDA-TFS group showed low serotonin tissue content in all the brain areas evaluated. However, when compared with the 6-OHDA group, higher values were detected in ipsi- and contralateral striatum $(p<0.02$ and $p<0.05$, respectively), as well as contralateral cortex $(p<0.001)$ and hippocampus $(p<0.001)$ (Figure 2$)$.

Concerning histamine tissue content, animals from the 6-OHDA-TFS group presented values similar to the Sham group. When compared with the 6-OHDA group, lower values were detected in ipsilateral cortex, hippocampus, and amygdala $(p<0.03, p<0.05$, and $p<0.004$, respectively) and contralateral amygdala $(p<0.02)$ (Figure 3 ).

The results obtained from the 6-OHDA-TFS group indicate that TFS applied daily for $2 \mathrm{~h}$ per day for 21 days does not avoid the loss of dopamine in the lesioned striatum. However, it protected peripheral structures from changes in biogenic amines induced by the toxin.

\section{Discussion}

The present study results indicate that the repetitive application of TFS for 21 days in normal animals did not modify the tissue content of dopamine, serotonin, and histamine in the different brain areas evaluated. However, repetitive TFS application avoids some of the long-term changes induced by the intrastriatal injection of 6-OHDA in biogenic amines in the striatum, cortex, hippocampus, and amygdala.

It is known that the dopamine and serotonin tissue levels in the striatum and other brain areas such as the cerebral cortex and the hippocampus, decrease as a consequence of 6-OHDA intrastriatal injection [23-25]. 6-OHDA selectively destroys dopaminergic neurons due to its high affinity to the dopamine transporter [26,27]. 6-OHDA can also destroy adjacent cells as a result of the formation of ROS [16,27]. This situation explains the simultaneous changes in dopamine and serotonin in different brain areas induced by 6-OHDA. In contrast, we found that 6-OHDA induces enhanced tissue levels of histamine in different brain areas. This effect is similar to the results previously reported by other authors in rats $[19,28]$ and patients with Parkinson's Disease $[29,30]$. The high tissue content of histamine may contribute to the neuroinflammation process produced by the toxin administration [31].

Our results reveal that the repetitive application of TFS for 21 days avoided some of the changes of the biogenic amines tissue content induced by the striatal injection of 
6-OHDA. These protective effects are similar to those induced by other strategies of neuromodulation. Deep brain stimulation improves the survival of dopaminergic neurons and avoids alterations in the tissue content of dopamine and serotonin in patients with Parkinson's Disease [22]. Likewise, direct current stimulation applied for 4 weeks prevents the depletion of dopaminergic neurons induced by 6-OHDA, improving the motor alterations in the animals [32].

In the present study, animals receiving 6-OHDA and TFS showed a higher tissue content of dopamine in the different evaluated brain areas, when compared with the 6OHDA group. Similarly, neuromodulation strategies such as high-frequency stimulation in 6-OHDA lesioned rats augment the extracellular levels of dopamine in the striatum [33].

It is known that behavioral and mood alterations in patients with Parkinson's Disease are associated with reduced plasma levels of serotonin, suggesting its low neurotransmission [34]. Studies indicate that deep brain stimulation decreases serotoninergic neurotransmission [35-37]. Electrical stimulation of the subthalamic nucleus, a strategy used to reduce motor dysfunction in Parkinson's disease patients, results in more evident behavioral and mood alterations $[38,39]$. This evidence supports that deep brain stimulation exacerbates the reduced serotoninergic neurotransmission associated with Parkinson's Disease. In the present study, we found that rats from the 6-OHDA-TFS group showed higher tissue content of serotonin in contrast with the 6-OHDA group. Our results support that TFS is more effective than deep brain stimulation to avoid serotonin changes induced by 6-OHDA.

Studies indicate that high histamine levels in arkinsonian basal ganglia circuitry represent a compensatory mechanism for regulating the firing patterns of subthalamic neurons and decreasing motor dysfunction [40]. Nevertheless, the increased levels of histamine in other brain areas could lead to neuroinflammation with a consequent neuronal degeneration found in neurological disorders such as Parkinson's disease [31]. Indeed, it is known that $90 \%$ of the histamine in brain areas such as the hippocampus is released from mast cells [41] that participate in neuroinflammation and cell damage [42,43]. In the present study, we found that TFS avoids the increased levels of histamine-induced by 6-OHDA in the ipsilateral striatum, cortex, and hippocampus and bilateral amygdalae. These results suggest that TFS represents a neuroprotective strategy in the 6-OHDA lesioned rats.

It is also important to mention that the repetitive application of TFS in normal animals did not produce changes in the brain tissue content of the biogenic amines evaluated. In contrast, the repetitive application of transcranial magnetic stimulation increases the striatal dopamine levels in control rats [44]. This group of evidence supports that TFS represents a good neuromodulatory strategy to avoid the toxic effects of 6-OHDA in the brain.

The unilateral application of 6-OHDA induces cell death and oxidative stress [45], both of these phenomena could be associated with changes in the biogenic amines. The present study presents important limitations for possible clinical implications of the TFS. One limitation is the lack of behavioral and histological evaluation. Future studies should be carried out to test whether TFS can avoid the behavioral and cellular changes induced by 6-OHDA. Another important limitation is that there was a limited number of animals used for each experimental group. Although this situation restricts the significance of the data obtained, the effects of TFS on the tissue levels of biogenic amines are evident.

\section{Materials and Methods}

\subsection{Animals}

Adult male Wistar rats, initially weighing 250-300 g, were individually housed at $22{ }^{\circ} \mathrm{C}$ and maintained on a 12-h light/dark cycle. Animals had free access to food and water. According to the Mexican Official Standard (NOM-062-ZOO-1999) and the Ethical Committee of the Center for Research and Advanced Studies (Protocol \#175/15 with approval date of 04/05/2016), the present study was carried out. 


\subsection{Surgery and Intrastriatal Injection of 6-OHDA}

Rats were anesthetized with a mixture of ketamine $(80 \mathrm{mg} / \mathrm{kg}$, i.p.) and xylazine (20 mg/kg, i.m.). Through a trepan in the skull, an intrastriatal injection of 6-OHDA was applied $(4 \mu \mathrm{g} / \mu \mathrm{L}$ in ascorbic acid $0.01 \%, 0.9 \%$ de $\mathrm{NaCl}$, total $4 \mu \mathrm{L})$. The toxin was injected slowly $(0.5 \mu \mathrm{L} / \mathrm{min})$ into the right striatum ( $\mathrm{AP},+0.7 \mathrm{~mm}$ from Bregma; lateral $3.8 \mathrm{~mm}$; ventral from the dura $5.0 \mathrm{~mm}$ ). Then, a $6 \mathrm{~mm}$ diameter TCRE attached to male connector pins was placed centered on the cranium, $5 \mathrm{~mm}$ behind Bregma. Four stainless steel screws were threaded into the cranium over the frontal and cerebellar cortices and the electrode assembly was affixed to the skull with dental acrylic. Animals were allowed to recover for 2 days before any further manipulation.

\subsection{Experimental Groups}

6-OHDA-TFS group $(n=6)$. Two days after implanting and injection with 6-OHDA, animals received TFS daily for $2 \mathrm{~h}$ per day for 21 days. TFS consisted of $200 \mu$ s symmetrical biphasic square charge-balanced constant current pulses at a rate of $300 \mathrm{~Hz}$ and an intensity of $100 \mu \mathrm{A}$. TFS was applied through the outer ring (external diameter of $6.0 \mathrm{~mm}$ ) and the disc of a TCRE (with the middle ring floating). For this purpose, we used two Grass Technologies S48 square pulse stimulators each with an SIU-C constant current stimulus isolation unit (Grass Technologies, West Warwick, RI). One S48 provided the positive pulses and the other provided the negative pulses. The day after the last TFS, rats were killed by decapitation, and the brain was obtained. Striatum, cortex, amygdala, and hippocampus, ipsi- and contralateral to the place of 6-OHDA injection, were dissected and immediately stored in polypropylene Eppendorf tubes at $-70^{\circ} \mathrm{C}$.

6-OHDA group $(n=6)$. Rats were manipulated as indicated previously for the 6OHDA-TFS group, except that they did not receive TFS.

TFS group $(n=6)$. Rats were manipulated as indicated previously for the 6-OHDATFS group, except that they received an intrastriatal injection of the vehicle instead of 6-OHDA.

Sham group $(n=6)$. Rats were manipulated as indicated previously for the 6-OHDA group, except that they received an intrastriatal injection of the vehicle instead of toxin.

\subsection{Evaluation of Tissue Content of Biogenic Amines by Chromatography}

Brain tissue samples (10-100 mg each) were homogenized on ice in $90 \mu \mathrm{L} \mathrm{HClO} 40.1 \mathrm{M}$ using a tissue homogenizer. The homogenate was centrifuged at 13,000 rpm for $15 \mathrm{~min}$ at $4{ }^{\circ} \mathrm{C}$ and the resulting supernatant was filtrated by a Nalgene-nylon $0.45 \mu \mathrm{m}$ filter and stored at $-70^{\circ} \mathrm{C}$ until use.

Then, $20 \mu \mathrm{L}$ of the stored sample was injected into the solvent stream of a highperformance liquid chromatography system. Dopamine and serotonin levels were eluted using a reversed-phase column $\left(\mathrm{C} 18,3 \mu \mathrm{m} ; 2.1 \times 50 \mathrm{~mm}\right.$; Atlantis, Waters ${ }^{\circledR}$, Milford, MA, USA) coupled to a pre-column (Atlantis, Waters ${ }^{\circledR}$, Milford, MA, USA) and mobile phase solution containing sodium acetate $25 \mathrm{mM}$, EDTA $0.01 \mathrm{mM}$; citric acid $25 \mathrm{mM}$ and 1-octane sulfonic acid $1 \mathrm{mM}$ dissolved in milli- $\mathrm{Q}$ water and mixed with acetonitrile in a proportion of 95:5, pH $3.35 \pm 0.05$ at a flow rate of $0.35 \mathrm{~mL} / \mathrm{min}$. Dopamine and serotonin detection was performed by a single-channel electrochemical detector (Waters ${ }^{\circledR}$ model 2465, Milford, MA, USA) at $450 \mathrm{mV}$ at $30^{\circ} \mathrm{C}$.

For histamine levels, $15 \mu \mathrm{L}$ of the sample was mixed with $10 \mu \mathrm{L}$ OPA-NAC solution $\mathrm{pH} 9.3 \pm 0.05$ [46] in a vial. It was eluted using a reversed-phase column $(\mathrm{C} 18,4 \mu \mathrm{m}$; $3.9 \times 150 \mathrm{~mm}$; Nova-Pak, Waters ${ }^{\circledR}$, Milford, MA, USA). A Ternary elution system was employed in a gradient flow with aqueous acetate phosphate buffer $\mathrm{pH} 5.05 \pm 0.05$ (eluent A), HPLC grade acetonitrile (eluent B), and milli-Q water (eluent C) [47]. The detection of histamine was performed by fluorescence detector (Waters ${ }^{\circledR}$ model 474, Milford, MA, USA) with an excitation wavelength of $360 \mathrm{~nm}$, an emission wavelength of $450 \mathrm{~nm}$, and a gain value of 100 . Peak height measurements quantified all the biogenic amines against standard solutions. 
The pellet obtained from the homogenization of each brain sample was resuspended in fresh $\mathrm{NaOH} 0.1 \mathrm{~N}$, and protein levels were determined by the method of Bradford [48]. The obtained values allowed expressing the data resulting from the high-performance liquid chromatography in $\mu \mathrm{M} / \mathrm{mg}$ of proteins.

\subsection{Statistical Analysis and Sample Size}

Previous studies indicate that six animals per group is the minimum sample size to detect significant differences in pilot studies evaluating quantitative variables [49]. According to this notion, the sample size for the present study was six rats per group.

Values were expressed as mean \pm S.E.M. The results obtained were analyzed with ANOVA followed by the post hoc Tukey test. In all statistical comparisons, $p<0.05$ was used as the criterion for significance.

\section{Conclusions}

TFS is a non-invasive neuromodulatory strategy with neuroprotective effects that also avoids most of the neurochemical abnormalities caused by the intrastriatal injection of 6-OHDA in the dopaminergic, serotoninergic, and histaminergic systems. Further research is needed to determine if TFS is able to protect the animals from the motor dysfunction and cell damage induced by the toxin.

Author Contributions: Conceptualization, W.B., C.E.S.-G., O.A.-C., and L.R.; methodology, C.E.S.-G., D.P.-P., O.A.-C., and D.F.-B.; formal analysis, L.R.; resources, W.B. and L.R.; data curation, C.E.S.-G. and D.P.-P.; writing—original draft preparation, D.P.-P. and L.R.; writing—review and editing, D.P.-P., W.B., and L.R.; supervision, W.B. and L.R.; project administration, W.B. and L.R.; funding acquisition, W.B. and L.R. All authors have read and agreed to the published version of the manuscript.

Funding: This research was partially funded by the National Institutes of Health, the National Institute of Neurological Disorders and Stroke, grants number R21NS061335 and R21TW009384.

Institutional Review Board Statement: The study was conducted according to the Mexican Official Standard (NOM-062-ZOO-1999) and the Ethical Committee of the Center for Research and Advanced Studies (Protocol \#175/15).

Informed Consent Statement: Not applicable.

Data Availability Statement: Data is contained within the article.

Acknowledgments: The authors would like to thank the technical support of Francia Carmona-Cruz for the HPLC experiments. This study was partially supported by the National Council of Science and Technology of Mexico (CONACYT, scholarship No. 622940 given to D.P.-P. and scholarship No. 489736 given to D.F.-B.).

Conflicts of Interest: The authors declare no conflict of interest.

\section{References}

1. Edwards, C.A.; Kouzani, A.; Lee, K.H.; Ross, E.K. Neurostimulation Devices for the Treatment of Neurologic Disorders. Mayo Clin. Proc. 2017, 92, 1427-1444. [CrossRef]

2. Vizcarra, J.A.; Situ-Kcomt, M.; Artusi, C.A.; Duker, A.P.; Lopiano, L.; Okun, M.S.; Espay, A.J.; Merola, A. Subthalamic deep brain stimulation and levodopa in Parkinson's disease: A meta-analysis of combined effects. J. Neurol. 2019, 266, 289-297. [CrossRef]

3. Chang, B.; Xu, J. Deep brain stimulation for refractory temporal lobe epilepsy: A systematic review and meta-analysis with an emphasis on alleviation of seizure frequency outcome. Childs. Nerv. Syst. 2018, 34, 321-327. [CrossRef]

4. Dang, T.T.H.; Rowell, D.; Connelly, L.B. Cost-Effectiveness of Deep Brain Stimulation With Movement Disorders: A Systematic Review. Mov. Disord. Clin. Pract. 2019, 6, 348-358. [CrossRef] [PubMed]

5. Akazawa, M.; Konomura, K.; Shiroiwa, T. Cost-Minimization Analysis of Deep-Brain Stimulation Using National Database of Japanese Health Insurance Claims. Neuromodulation 2018, 21, 548-552. [CrossRef]

6. Besio, W.G.; Koka, K.; Cole, A.J. Effects of non-invasive transcutaneous electrical stimulation via concentric ring electrodes on pilocarpine-induced status epilepticus in rats. Epilepsia 2007, 48, 2273-2279. [CrossRef] [PubMed]

7. Besio, W.G.; Gale, K.N.; Medvedev, A.V. Possible therapeutic effects of transcutaneous electrical stimulation via concentric ring electrodes. Epilepsia 2010, 51 (Suppl. 3), 85-88. [CrossRef] [PubMed] 
8. Besio, W.G.; Liu, X.; Wang, L.; Medvedev, A.V.; Koka, K. Transcutaneous focal electrical stimulation via concentric ring electrodes reduces synchrony induced by pentylenetetrazole in beta and gamma bands in rats. Int. J. Neural Syst. 2011, 21, 139-149. [CrossRef]

9. Makeyev, O.; Luna-Munguía, H.; Rogel-Salazar, G.; Liu, X.; Besio, W.G. Non-invasive transcranial focal stimulation via tripolar concentric ring electrodes lessens behavioral seizure activity of recurrent pentylenetetrazole administrations in rats. IEEE Trans. Neural Syst. Rehabil. Eng. 2013, 21, 383-390. [CrossRef]

10. Besio, W.; Cuellar-Herrera, M.; Luna-Munguia, H.; Orozco-Suárez, S.; Rocha, L. Effects of transcranial focal electrical stimulation alone and associated with a sub-effective dose of diazepam on pilocarpine-induced status epilepticus and subsequent neuronal damage in rats. Epilepsy Behav. 2013, 28, 432-436. [CrossRef] [PubMed]

11. Pérez-Pérez, D.; Castañeda-Cabral, J.L.; Orozco-Suárez, S.; Sotelo, J.; Besio, W.; Rocha, L. Noninvasive transcranial focal stimulation affects the convulsive seizure-induced P-glycoprotein expression and function in rats. Epilepsy Behav. 2021, 115, 107659. [CrossRef]

12. Santana-Gómez, C.E.; Alcántara-González, D.; Luna-Munguía, H.; Bañuelos-Cabrera, I.; Magdaleno-Madrigal, V.; Fernández-Mas, R.; Besio, W.; Rocha, L. Transcranial focal electrical stimulation reduces the convulsive expression and amino acid release in the hippocampus during pilocarpine-induced status epilepticus in rats. Epilepsy Behav. 2015, 49, 33-39. [CrossRef]

13. Blandini, F.; Armentero, M.-T. Animal models of Parkinson's disease. FEBS J. 2012, 279, 1156-1166. [CrossRef] [PubMed]

14. Perfeito, R.; Cunha-Oliveira, T.; Rego, A.C. Reprint of: Revisiting oxidative stress and mitochondrial dysfunction in the pathogenesis of Parkinson disease-resemblance to the effect of amphetamine drugs of abuse. Free Radic. Biol. Med. 2013, 62, 186-201. [CrossRef]

15. Qu, L.; Wang, Y.; Zhang, H.-T.; Li, N.; Wang, Q.; Yang, Q.; Gao, G.-D.; Wang, X.-L. 6-OHDA induced calcium influx through $\mathrm{N}$-type calcium channel alters membrane properties via PKA pathway in substantia nigra pars compacta dopaminergic neurons. Neurosci. Lett. 2014, 575, 1-6. [CrossRef]

16. Hernandez-Baltazar, D.; Zavala-Flores, L.M.; Villanueva-Olivo, A. The 6-hydroxydopamine model and parkinsonian pathophysiology: Novel findings in an older model. Neurologia 2017, 32, 533-539. [CrossRef]

17. Zhang, W.Q.; Tilson, H.A.; Nanry, K.P.; Hudson, P.M.; Hong, J.S.; Stachowiak, M.K. Increased dopamine release from striata of rats after unilateral nigrostriatal bundle damage. Brain Res. 1988, 461, 335-342. [CrossRef]

18. Eskow Jaunarajs, K.L.; George, J.A.; Bishop, C. L-DOPA-induced dysregulation of extrastriatal dopamine and serotonin and affective symptoms in a bilateral rat model of Parkinson's disease. Neuroscience 2012, 218, 243-256. [CrossRef]

19. Nowak, P.; Noras, L.; Jochem, J.; Szkilnik, R.; Brus, H.; Körossy, E.; Drab, J.; Kostrzewa, R.M.; Brus, R. Histaminergic activity in a rodent model of Parkinson's disease. Neurotox. Res. 2009, 15, 246-251. [CrossRef] [PubMed]

20. Liu, C.-Q.; Chen, Z.; Liu, F.-X.; Hu, D.-N.; Luo, J.-H. Involvement of brain endogenous histamine in the degeneration of dopaminergic neurons in 6-hydroxydopamine-lesioned rats. Neuropharmacology 2007, 53, 832-841. [CrossRef]

21. Nishida, N.; Huang, Z.-L.; Mikuni, N.; Miura, Y.; Urade, Y.; Hashimoto, N. Deep brain stimulation of the posterior hypothalamus activates the histaminergic system to exert antiepileptic effect in rat pentylenetetrazol model. Exp. Neurol. 2007, 205, 132-144. [CrossRef]

22. Herrington, T.M.; Cheng, J.J.; Eskandar, E.N. Mechanisms of deep brain stimulation. J. Neurophysiol. 2016, 115, 19-38. [CrossRef]

23. Zhang, S.; Gui, X.-H.; Xue, Z.-F.; Huang, L.-P.; Fang, R.-M.; Ke, X.-H.; Li, L.; Fang, Y.-Q. Dynamic of neurochemical alterations in striatum, hippocampus and cortex after the 6-OHDA mesostriatal lesion. Int. J. Dev. Neurosci. 2014, 36, 32-37. [CrossRef] [PubMed]

24. Branchi, I.; D’Andrea, I.; Armida, M.; Carnevale, D.; Ajmone-Cat, M.A.; Pèzzola, A.; Potenza, R.L.; Morgese, M.G.; Cassano, T.; Minghetti, L.; et al. Striatal 6-OHDA lesion in mice: Investigating early neurochemical changes underlying Parkinson's disease. Behav. Brain Res. 2010, 208, 137-143. [CrossRef]

25. Santiago, R.M.; Barbiero, J.; Gradowski, R.W.; Bochen, S.; Lima, M.M.S.; Da Cunha, C.; Andreatini, R.; Vital, M.A.B.F. Induction of depressive-like behavior by intranigral 6-OHDA is directly correlated with deficits in striatal dopamine and hippocampal serotonin. Behav. Brain Res. 2014, 259, 70-77. [CrossRef]

26. Pantic, I.; Cumic, J.; Skodric, S.R.; Dugalic, S.; Brodski, C. Oxidopamine and oxidative stress: Recent advances in experimental physiology and pharmacology. Chem. Biol. Interact. 2021, 336, 109380. [CrossRef]

27. Varešlija, D.; Tipton, K.F.; Davey, G.P.; McDonald, A.G. 6-Hydroxydopamine: A far from simple neurotoxin. J. Neural Transm. 2020, 127, 213-230. [CrossRef]

28. Brus, R.; Jochem, J.; Nowak, P.; Adwent, M.; Boroń, D.; Brus, H.; Kostrzewa, R.M. Effect of pre- and postnatal manganese exposure on brain histamine content in a rodent model of Parkinson's disease. Neurotox. Res. 2012, 21, 143-148. [CrossRef]

29. Rinne, J.O.; Anichtchik, O.V.; Eriksson, K.S.; Kaslin, J.; Tuomisto, L.; Kalimo, H.; Röyttä, M.; Panula, P. Increased brain histamine levels in Parkinson's disease but not in multiple system atrophy. J. Neurochem. 2002, 81, 954-960. [CrossRef]

30. Anichtchik, O.V.; Rinne, J.O.; Kalimo, H.; Panula, P. An altered histaminergic innervation of the substantia nigra in Parkinson's disease. Exp. Neurol. 2000, 163, 20-30. [CrossRef]

31. Vizuete, M.L.; Merino, M.; Venero, J.L.; Santiago, M.; Cano, J.; Machado, A. Histamine infusion induces a selective dopaminergic neuronal death along with an inflammatory reaction in rat substantia nigra. J. Neurochem. 2000, 75, 540-552. [CrossRef] 
32. Feng, X.-J.; Huang, Y.-T.; Huang, Y.-Z.; Kuo, C.-W.; Peng, C.-W.; Rotenberg, A.; Juan, C.-H.; Pei, Y.-C.; Chen, Y.-H.; Chen, K.-Y.; et al. Early transcranial direct current stimulation treatment exerts neuroprotective effects on 6-OHDA-induced Parkinsonism in rats. Brain Stimul. 2020, 13, 655-663. [CrossRef]

33. He, Z.; Jiang, Y.; Xu, H.; Jiang, H.; Jia, W.; Sun, P.; Xie, J. High frequency stimulation of subthalamic nucleus results in behavioral recovery by increasing striatal dopamine release in 6-hydroxydopamine lesioned rat. Behav. Brain Res. 2014, 263, 108-114. [CrossRef]

34. Tong, Q.; Zhang, L.; Yuan, Y.; Jiang, S.; Zhang, R.; Xu, Q.; Ding, J.; Li, D.; Zhou, X.; Zhang, K. Reduced plasma serotonin and 5-hydroxyindoleacetic acid levels in Parkinson's disease are associated with nonmotor symptoms. Parkinsonism Relat. Disord. 2015, 21, 882-887. [CrossRef]

35. Kocabicak, E.; Jahanshahi, A.; Schonfeld, L.; Hescham, S.-A.; Temel, Y.; Tan, S. Deep Brain Stimulation of the Rat Subthalamic Nucleus Induced Inhibition of Median Raphe Serotonergic and Dopaminergic Neurotransmission. Turk. Neurosurg. 2015, 25, 721-727. [CrossRef]

36. Faggiani, E.; Delaville, C.; Benazzouz, A. The combined depletion of monoamines alters the effectiveness of subthalamic deep brain stimulation. Neurobiol. Dis. 2015, 82, 342-348. [CrossRef]

37. Tan, S.K.H.; Hartung, H.; Visser-Vandewalle, V.; Steinbusch, H.W.M.; Temel, Y.; Sharp, T. A combined in vivo neurochemical and electrophysiological analysis of the effect of high-frequency stimulation of the subthalamic nucleus on 5-HT transmission. Exp. Neurol. 2012, 233, 145-153. [CrossRef]

38. Navailles, S.; De Deurwaerdère, P. Contribution of serotonergic transmission to the motor and cognitive effects of high-frequency stimulation of the subthalamic nucleus or levodopa in Parkinson's disease. Mol. Neurobiol. 2012, 45, 173-185. [CrossRef]

39. Tommasi, G.; Lanotte, M.; Albert, U.; Zibetti, M.; Castelli, L.; Maina, G.; Lopiano, L. Transient acute depressive state induced by subthalamic region stimulation. J. Neurol. Sci. 2008, 273, 135-138. [CrossRef]

40. Zhuang, Q.-X.; Li, G.-Y.; Li, B.; Zhang, C.-Z.; Zhang, X.-Y.; Xi, K.; Li, H.-Z.; Wang, J.-J.; Zhu, J.-N. Regularizing firing patterns of rat subthalamic neurons ameliorates parkinsonian motor deficits. J. Clin. Invest. 2018, 128, 5413-5427. [CrossRef] [PubMed]

41. Panula, P.; Pirvola, U.; Auvinen, S.; Airaksinen, M.S. Histamine-immunoreactive nerve fibers in the rat brain. Neuroscience 1989, 28, 585-610. [CrossRef]

42. Kempuraj, D.; Thangavel, R.; Natteru, P.A.; Selvakumar, G.P.; Saeed, D.; Zahoor, H.; Zaheer, S.; Iyer, S.S.; Zaheer, A. Neuroinflammation Induces Neurodegeneration. J. Neurol. Neurosurg. Spine 2016, 1, 1003.

43. Valle-Dorado, M.G.; Santana-Gómez, C.E.; Orozco-Suárez, S.A.; Rocha, L. The mast cell stabilizer sodium cromoglycate reduces histamine release and status epilepticus-induced neuronal damage in the rat hippocampus. Neuropharmacology 2015, 92, 49-55. [CrossRef]

44. Kanno, M.; Matsumoto, M.; Togashi, H.; Yoshioka, M.; Mano, Y. Effects of acute repetitive transcranial magnetic stimulation on dopamine release in the rat dorsolateral striatum. J. Neurol. Sci. 2004, 217, 73-81. [CrossRef]

45. Baluchnejadmojarad, T.; Mansouri, M.; Ghalami, J.; Mokhtari, Z.; Roghani, M. Sesamin imparts neuroprotection against intrastriatal 6-hydroxydopamine toxicity by inhibition of astroglial activation, apoptosis, and oxidative stress. Biomed. Pharmacother. 2017, 88, 754-761. [CrossRef]

46. Kutlán, D.; Molnár-Perl, I. New aspects of the simultaneous analysis of amino acids and amines as their o-phthaldialdehyde derivatives by high-performance liquid chromatography. Analysis of wine, beer and vinegar. J. Chromatogr. A 2003, 987, 311-322. [CrossRef]

47. Liu, H.; Sañuda-Peña, M.C.; Harvey-White, J.D.; Kalra, S.; Cohen, S.A. Determination of submicromolar concentrations of neurotransmitter amino acids by fluorescence detection using a modification of the 6-aminoquinolyl-N-hydroxysuccinimidyl carbamate method for amino acid analysis. J. Chromatogr. A 1998, 828, 383-395. [CrossRef]

48. Kruger, N.J. The Bradford method for protein quantitation. Methods Mol. Biol. 1994, 32, 9-15. [CrossRef]

49. Allgoewer, A.; Mayer, B. Sample size estimation for pilot animal experiments by using a Markov Chain Monte Carlo approach. Altern. Lab. Anim. 2017, 45, 83-90. [CrossRef] 